\title{
Ventricular Tachycardia due to Long QT Syndrome Associated to Non-Cardiac Pharmacological Agents
}

Keywords: Ventricular tachycardia; Long QT syndrome; Torsade de pointes; Non-cardiac drugs

\section{Editorial}

The prolongation of the QT interval of the electrocardiogram is known to be associated to ventricular arrhythmias. Although, anti-arrhythmic drugs are known to prolong the QT interval, this is also prolonged by several non-cardiac drugs that are utilized in the clinical setting [1-6]. The QT interval, a measurement of ventricular systole and diastole, is the electrocardiographic expression of the ventricular depolarization and repolarization. The QT interval is measured from the onset of the QRS to the end of the T wave. This task is not always easy to perform since the last portion of the $\mathrm{T}$ wave often camouflages with the isoelectric line.

The influx and efflux of sodium, potassium, and calcium through the cell membrane determines the physiologic depolarization and repolarization of the cardiac cell. Normal depolarization involves a rapid influx of sodium across the cell plasma membrane. Repolarization occurs when the efflux of potassium exceeds the declining inflow of sodium and calcium. These ion currents utilize specific channels that are under the influence of multiple factors. The long QT syndrome is characterized by QT interval prolongation and a tendency to develop a potentially lethal ventricular tachycardia [1,2]. Several anti-arrhythmic drugs, as well as some non-cardiac medications, block a specific potassium channel: $\mathrm{I}_{\mathrm{Kr}}$. In the case of the anti-arrhythmic drugs, inhibition of $\mathrm{I}_{\mathrm{Kr}}$ channels is the mechanism for the drug's therapeutic effect. Non-cardiac drugs that cause the long QT syndrome block these channels incidentally.

Although, the long QT syndrome was associated with the use of anti-arrhythmic drugs at the beginning, this prolongation may complicate the use of a large group of non-cardiac medications frequently used in internal medicine. Mostly prescribed by general physicians and internists, these non-cardiac drugs are commonly prescribed agents, namely, antibiotics, anti-histamines and anti-psychotic agents. It has been estimated that up to $3 \%$ of all drug prescriptions are for medications that may prolong the QT interval [3]. Recognition of the long QT syndrome due to non-cardiac drugs is therefore of great importance. The proarrhythmic potential of non-cardiac medications can be estimated experimentally in cell cultures, in isolated hearts, as well as, in animal models [4-6]. For example, drug concentrations at which $\mathrm{I}_{\mathrm{Kr}}$ channels are blocked can be determined in cell cultures. However, these models only provide rough estimates of a given drug's proarrhythmic potential and have limited clinical implications [4].

About five decades ago, Jervell and Lange-Nielsen described the congenital syndrome of deafness, long QT and malignant arrhythmias in infancy [7]. A milder, more common, form of the congenital long QT syndrome was subsequently described by Romano and Ward $[8,9]$. At that time, the pro-arrhythmic effect of quinidine [10] and some non-cardiac medications [11] were

Eolume 5 Issue 5 - 2016
Osmar Antonio Centurián ${ }^{* 1,2}$
${ }^{1}$ Department of Health Sciences's Investigation, Sanatorio
Metropolitano, Fernando de la Mora, Paraguay
${ }^{2}$ Cardiology Division, First Department of Internal Medicine,
Clinic Hospital, Asunción National University, San Lorenzo,
Paraguay
*Corresponding author: Osmar Antonio Centurión,
Professor of Medicine, Asuncion National University,
Department of Health Sciences's Investigation, Sanatorio
Metropolitano, Teniente Ettiene 215 c/ Ruta Mariscal
Estigarribia,Fernando de la Mora, Paraguay, Tel: 595-21-
498200; Fax: 595-21-205630; Email: osmarcenturion@
hotmail.com
Received: April 26, 2016 | Published: May 06, 2016

also reported. Although for years the congenital and acquired forms of the long QT syndrome were considered to be two distinct entities [12], it is now clear that all forms of the long QT syndrome are caused by dysfunction of ion channels in the membrane of cardiomyocytes. This ion channel dysfunction may be due to mutations in genes that encode the channel proteins in the congenital syndrome, or may result from the effects of pharmacological agents in the acquired disease [13].

Several non-cardiac medications like antibiotics, antihistamines and anti-psychotic drugs, block potassium channels in myocardial cells and may thus prolong the QT interval triggering a life-threatening ventricular arrhythmia known as torsade de pointes [14-16]. Most patients with drug induced torsade de pointes have additional clinical risk factors that are readily identifiable such as female gender, organic heart disease, hypokalemia and a history of long QT or drug-induced arrhythmias. For patients without these risk factors it is neither practical nor necessary to implement screening measures such as electrocardiography or measuring serum potassium levels before therapy is initiated. However it is important to consider other preventive measures. For example, it should be avoided the concurrent administration of two or more drugs that prolong the QT interval, as well as, the administration of medications that impair the metabolism of a QT-prolonging drug. Preventing torsade de pointes during drug therapy largely depends on the early identification of patients prone to develop this condition. Predictors of increased risk for QT prolongation with non-cardiac drugs have been described [16]. Of these risk factors, mutations in genes encoding ion channels or drug-metabolizing enzymes can only be detected in selected centers. Moreover, known mutations or polymorphisms associated with an increased risk for arrhythmias are present in only $4-15 \%$ of patients with drug- 
induced torsade de pointes [14]. In the future, genetic testing may be routinely available to identify patients with mutant ion channels or drug-metabolizing enzyme systems [15].

There is an increased incidence of ventricular arrhythmias in the setting of organic heart disease. Patients with structural heart disease, particularly those with marked left ventricular hypertrophy and heart failure, have abnormal repolarizing currents in the ventricle. Because of their reduced "repolarization reserve" [16] they are at increased risk of developing torsade de pointes when treated with medications that prolong repolarization. It was observed that an average of $42 \%$ of patients with torsade de pointes due to non-cardiac medications had structural heart disease. About $19 \%$ of patients developed torsade de pointes with anti-histamines, $46 \%$ with psychiatric drugs and $52 \%$ with antibiotics $[17,18]$. Concomitant administration of two drugs that lead to QT prolongation should be avoided whenever possible, especially if additional risk factors, namely, female gender, heart disease, are present. Although the risk of torsade de pointes is directly related to the degree of QT prolongation, the exact risk of arrhythmia cannot be predicted by the QT interval. Pro-arrhythmia from non-cardiac drugs appears to be a relatively late complication. In contrast to the pro-arrhythmic effects of anti-arrhythmic medications, which usually appear within 48-72 hours from the onset of therapy [19], only $19 \%$ of arrhythmias due to non-cardiac drugs given orally will occur within 72 hours from onset of therapy, and $60 \%$ of arrhythmias will occur more than a week after the onset of therapy. If combination therapy is necessary, serial electrocardiograms should be obtained.

It is essential to consider some interesting facts in order to perform an adequate diagnosis and proper therapeutic management. First, the list of medications known to cause the long QT syndrome is constantly expanding. Second, the long QT syndrome should always be considered a potential side effect of drug administration. Third, there are several accessible sources, including Web sites that provide updated information on drug interactions and their direct effects on the QT interval. Fourth, the most important preventive measure is avoidance of drug interactions that prolong the QT interval, and the risk of torsade de pointes may be heightened by the direct effect of multiple drugs on the QT interval or by impaired metabolism of a QT prolonging medication by an additional drug [20-24]. To have these facts in mind will lead to simple precautions and preventive measures that can minimize the risk of serious ventricular arrhythmias in patients taking multiple medications.

\section{References}

1. Mazzanti A, Maragna R, Faragli A, Monteforte N, Bloise R, et al (2016) Gene-Specific Therapy With Mexiletine Reduces Arrhythmic Events in Patients With Long QT Syndrome Type 3. J Am Coll Cardiol 67(9):1053-1058

2. Arbelo E, Sarquella-Brugada G, Brugada J (2016) Gene-Specific Therapy for Congenital Long QT Syndrome: Are We There Yet? J Am Coll Cardiol 67(9): 1059-1061.

3. De Ponti F, Poluzzi E, Montanaro N (2000) QT-interval prolongation by non-cardiac drugs: lessons to be learned from recent experience. Eur J Clin Pharmacol 56(1): 1-18.
4. Haverkamp W, Breithardt G, Camm AJ, Janse MJ, Rosen MR, et al. (2000) The potential for QT prolongation and proarrhythmia by nonantiarrhythmic drugs: clinical and regulatory implications. Report of a Policy Conference of the European Society of Cardiology. Cardiovasc Res 47(2): 219-233.

5. Zabel M, Hohnloser SH, Behrens S, et al. (1997) Electrophysiologic features of torsade de pointes: insights from a new rabbit heart model. J Cardiovasc Electrophysiol 8(10): 1148-1158.

6. Carlsson L, Almgren O, Duker G (1990) QTU-prolongation and torsade de pointes induced by putative class III antiarrhythmic agents in the rabbit: Etiology and interventions. J Cardiovasc Pharmacol 16(2): 276-285.

7. Jervell A, Lange-Nielsen F (1957) Congenital deaf-mutism, functional heart disease with prolongation of the Q-T interval and sudden death. Am Heart J 54: 59-68.

8. Romano C, Gemme G, Pongiglione R (1963) [Rare Cardiac Arrythmias of the Pediatric Age. Ii. Syncopal Attacks Due To Paroxysmal Ventricular Fibrillation. (Presentation of 1st Case In Italian Pediatric Literature)]. Clin Pediat 45: 656-683.

9. Ward OC (1964) A new familial cardiac syndrome in children. J Irish Med Assoc 54: 103-106.

10. Selzer A, Wray HW (1964) Quinidine syncope. Paroxysmal ventricular fibrillation occurring during treatment of chronic atrial arrhythmias. Circulation 30: 17-26.

11. Schoonmaker F, Osten R, Greenfield J (1966) Thioridazine (mellaril) induced ventricular tachycardia controlled with an artificial pacemaker. Ann Intern Med 65(5): 1076-1078.

12. Jackman WM, Friday KJ, Anderson JL, Aliot EM, Clark M, et al. (1988) The long QT syndromes: a critical review, new clinical observations and a unifying hypothesis. Prog Cardiovasc Di 31(2): 115-172.

13. Sanguinetti MC, Jiang C, Curran ME, Keating MT (1995) A mechanistic link between an inherited and an acquired cardiac arrhythmia: HERG encodes the $\mathrm{I}_{\mathrm{Kr}}$ potassium channel. Cell 81(2): 229-307.

14. Sesti F, Abbott GW, Wei J, Murray KT, Saksena S, et al. (2000) A common polymorphism associated with antibiotic-induced cardiac arrhythmia. Proc Natl Acad Sci 97: 10613-10618.

15. Roden DM (2001) Pharmacogenetics and drug-induced arrhythmias. Cardiovasc Res 50: 224-231.

16. Roden DM (1998) Taking the "idio" out of "idiosyncratic:" Predicting torsades de pointes. Pacing Clin Electrophysiol 21(5): 1029-1034.

17. Viskin S, Zeltser D, Justo D, Amir H, Heller K, et al. (2002) Torsade de pointes due to medications administered for non-cardiac indications: most patients have risk factors that can be easily identified [abstract]. Pacing Clin Electrophysiol 24(II): 635

18. Viskin S, Justo D, Halkin A, Zeltser D (2003) Long QT syndrome caused by non-cardiac drugs. Prog Cardiovasc Dis 45(5): 415-427.

19. Viskin S, Barron HV, Heller K, Scheinman MM, Olgin J (1997) The treatment of atrial fibrillation: pharmacologic and non-pharmacologic strategies. Curr Prob Cardiol 22(2): 37-108.

20. Romero L, Trenor B, Yang PC, Saiz J, Clancy CE (2015) In silico screening of the impact of hERG channel kinetic abnormalities on channel block and susceptibility to acquired long QT syndrome. J Mol Cell Cardiol 87: 271-282.

21. Davis AM (2016) Torsades de Pointes: 50 Years Later, Can We See It Coming? Circ Arrhythm Electrophysiol 9(2): e003850. 
22. Takasugi N, Goto H, Takasugi M, Verrier RL, Kuwahara T, et al. (2016) Prevalence of Microvolt T-Wave Alternans in Patients With Long QT Syndrome and Its Association With Torsade de Pointes. Circ Arrhythm Electrophysiol 9(2): e003206.

23. Lazzerini PE, Capecchi PL, Laghi-Pasini F (2015) Long QT Syndrome: An Emerging Role for Inflammation and Immunity. Front Cardiovasc Med 2: 26
24. Kanters JK, Olesen MS, Christiansen M (2016) KCNE1 G38S polymorphism is not the cause of long QT syndrome. J Electrocardiol 49(2): 249-250. 